\title{
Biomarkers for efficacy of adjuvant chemotherapy following complete resection in NSCLC stages I-IIIA
}

\author{
Sandra Wallerek and Jens Benn Sørensen
}

Affiliation: Dept of Oncology, Finsen Centre, Copenhagen University Hospital, Copenhagen, Denmark.

Correspondence: Sandra Wallerek, Dept of Oncology 5073, Finsen Centre, Rigshospitalet (Copenhagen University Hospital), 9 Blegdamsvej, DK-2100 Copenhagen, Denmark. E-mail: sandra.wallerek.01aregionh.dk

ABSTRACT Biomarkers may be useful when deciding which nonsmall cell lung cancer (NSCLC) patients may benefit from adjuvant chemotherapy following complete resection and which chemotherapeutic agents may be used preferably in individual patients in order to maximise survival.

A literature search covering the period from 2003 to May, 2014 was conducted using PubMed and the following search terms: "non-small cell lung cancer", "NSCLC", "adjuvant chemotherapy", "randomized", "randomised”, "biomarkers", "prognostic", "predictive”. This review focuses on current knowledge of biomarkers for prognosis or efficacy of adjuvant treatment following complete resection in stage I-IIIA NSCLC patients.

This review includes results on 18 different biomarkers and five gene profiles. A statistically significant prognostic impact was reported for: iNTR, TUBB3, RRM1, ERCC1, BRCA1, p53, MRP2, MSH2, TS, mucin, BAG-1, pERK1/2, pAkt-1, microRNA, TopIIA, 15-gene profile, 92-gene profile, 31-gene profile and 14-gene profile. A statistically significant predictive impact was reported for: ERCC1, p53, MSH2, p27, TUBB3, PARP1, ATM, 37-gene profile, 31-gene profile, 15-gene profile and 92-gene profile.

Uncertainties regarding the optimal analysis method and cut-off levels for the individual markers may blur the prognostic or predictive signals. None of the possible predictive markers have been validated in prospective trials. Thus, there are no biomarkers ready to use in an adjuvant setting in NSCLC.

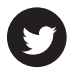

@ERSpublications

Further investigation and validation is required to explore biomarkers in completely resected NSCLC stage I-IIIA http://ow.ly/M0leE

\section{Introduction}

Lung cancer is the most common cause of cancer-related death worldwide, with 1.37 million lung cancer-related deaths in 2008 [1], which makes it the leading cause of cancer-related mortality in the world [2]. Lung cancer is often incurable, with a relatively short period of time from diagnosis to death. It is divided into small cell lung cancer, which accounts for approximately $12 \%$, and nonsmall cell lung cancer (NSCLC), which represents approximately $85 \%$ of lung cancer cases. Thus, NSCLC is one of the most common cancers, in both developed countries as well as worldwide, and prognosis is generally poor with an overall 5 -year survival of $10-15.9 \%[3,4]$.

\section{Adjuvant therapy: history and current guidelines}

Treatment of NSCLC patients depends on stage at the time of diagnosis. Stages I-IIIA are generally considered resectable, while stages IIIB-IV are not. Adjuvant chemotherapy (ACT) after complete surgery

This article has supplementary material available from err.ersjournals.com

Received: July 172014 | Accepted after revision: Oct 072014

Conflict of interest: None declared.

Provenance: Submitted article, peer reviewed.

Copyright CERS 2015. ERR articles are open access and distributed under the terms of the Creative Commons Attribution Non-Commercial Licence 4.0. 
has been extensively explored for stage I-IIIA patients. A meta-analysis from 1995, including 9387 patients, showed a $5 \%$ increase in 5 -year survival for patients with NSCLC stage I-III who underwent complete surgery and subsequent cisplatin-based ACT compared with patients without adjuvant treatment. However, these results were not statistically significant [5]. STEWART et al. [6] confirmed these results in a meta-analysis including data from 8147 patients in 30 randomised trials. They observed a significant increase (from $60 \%$ to $64 \%$ ) in 5-year survival in patients with stage II-IIIA who received ACT compared with patients without adjuvant treatment (hazard ratio (HR) 0.86, 95\% CI 0.81-0.93; p<0.000001). A later meta-analysis by PIGNON et al. [7] (LACE Collaborative Group) based on data from 4587 patients in five studies revealed that cisplatin-based ACT increased 5-year survival by $5.4 \%$, with statistically significant results for stages II and IIIA (HR for stage II 0.83, 95\% CI 0.73-0.95; HR for stage III 0.83, 95\% CI 0.72 0.94), while for stage IB there was a trend towards better prognosis with ACT, without statistical significance (HR 0.93, 95\% CI 0.78-1.10).

Accordingly, the current international standard is to administer ACT after complete surgery for NSCLC stage IIA-IIIA based on these meta-analyses [8]. It is also standard not to administer ACT after complete surgery for NSCLC stage IA, as no beneficial effect on the prognosis has been demonstrated. On the contrary, chemotherapy may have a negative influence on prognosis in this stage [8]. The situation in the case of stage IB is less clear and there is no universal standard for post-operative treatment in this stage despite a severe prognosis with 5-year survival being only of $43 \%$ in the new TNM (tumour, node, metastasis) staging classification from 2007 based on data from 3547 stage IB patients [9]. Several randomised studies have shown some numerical improvement of prognosis by ACT in this stage, but none were statistically significant. Accordingly, the European guidelines state adjuvant treatment for this group is optional [8], while the American guidelines recommend that ACT is not used for stage IB outside of clinical trials [10].

Thus, although it is currently standard to administer ACT in stages II-IIIA, there is room for improvement. In a population of 11536 patients with NSCLC stage I-IV, GoLDSTRAW et al. [9] reported that patients with stage IIA ( $4.2 \%$ of the NSCLC patients) had a 5 -year survival of $36 \%$, while stage IIB (19.5\% of patients) and IIIA (27.5\% of patients) had 5-year survivals of $25 \%$ and $19 \%$. Predictive biomarkers may be useful when deciding which chemotherapeutic agent should be used preferentially as ACT for an individual patient in order to improve prognosis. Prognostic and predictive markers may also assist in determining if patients within the stage IB group could benefit from adjuvant treatment and, if so, the preferred agents to employ. This review focuses on the current knowledge of prognostic and predictive markers in adjuvant treatment after complete surgery in stage I-III NSCLC.

\section{Definition of prognostic and predictive markers}

A prognostic marker has an association with a clinical outcome such as overall survival (OS) or disease-free survival (DFS). It may also be applied to the natural history of patients who receive no treatment following local treatment [11].

A predictive marker may be useful for choosing between treatment options. It can be used as an indicator of the likely benefit for a specific patient of a specific treatment [11]. In order to correctly identify a predictive factor one needs to have a treated group and a control group with untreated patients. Without a group of untreated patients for comparison it is impossible to determine if the factor is predictive or simply prognostic [12].

In this review, cut-off values defining positive/high or negative/low status are described briefly when mentioned in the text and discussed later in the Discussion section. For a more detailed description of how these cut-off values were reached we refer readers to the original articles.

\section{Materials and methods}

A literature search from 2003 to May 2014 was conducted using PubMed and the following search terms: "non-small cell lung cancer", "NSCLC", "adjuvant chemotherapy", "randomized", "randomised", "biomarkers", "prognostic", "predictive". Articles in languages other than English without an English abstract were excluded. This review focuses solely on biomarkers useful for patients with NSCLC early stages I-IIIA receiving chemotherapy in an adjuvant setting following complete resection. The tables show results presenting a biomarker's prognostic or predictive value in an adjuvant setting. Results regarding predictive markers were exclusively from articles with a control group, mostly randomised trials. Results from treatment of advanced stages or neo-adjuvant treatment are not presented in the tables, but results from such studies may be mentioned in the text for explanation, comparison or supplementary purposes. 


\section{Results}

Prognostic biomarkers

Data for prognostic biomarkers are shown in tables 1 and 2 .

\section{CD66b $b^{+}$neutrophil/CD8 $8^{+}$lymphocyte ratio}

Intratumoral $\mathrm{CD} 6 \mathrm{~b}^{+}$neutrophil/CD8 ${ }^{+}$lymphocyte ratio (iNTR) is a new biomarker first presented in 2012 by ILIE et al. [13]. In a study on patients with squamous cell histology, iNTR was used to explore the possible interaction between tumour cells and inflammatory cells. High iNTR was associated with poor prognosis with respect to both DFS and OS. High iNTR was defined as $\geqslant 1$ cells. $\mathrm{mm}^{-2}$. Patients with high and low iNTR had median DFS of 34 months and 43 months, respectively $(p<0.0001$ ), while median OS was 46 months and 60 months, respectively $(p<0.0001)$. These results suggest that iNTR may be a prognostic marker for high risk of disease recurrence and poor OS in patients with resectable NSCLC [13].

\section{$\beta$-tubulin class III}

$\beta$-tubulin class III (TUBB3) is the main component of microtubules. Microtubules are part of the cell's cytoskeleton and, therefore, crucial in cell division. Expression of TUBB3 may be seen in many different types of cancer cells [35]. High/positive expression of TUBB3 has been reported to be a prognostic marker for poor DFS and OS [14-16]. High levels were defined as greater than the median H-score by REIMAN et al. [15] and SÈve et al. [14]. OKUDA et al. [16] defined high expression as 2 using another score (range: 0-2). REIMAN et al. [15] presented data in 2012 from 1149 NSCLC patients in whom high expression of TUBB3 correlated with poor DFS and OS when compared with patients with low expression. Hazard ratios for DFS and OS were 1.30 (95\% CI 1.11-1.53; $\mathrm{p}=0.001)$ and 1.27 (95\% CI 1.07-1.51; $\mathrm{p}=0.008$ ), respectively.

\section{Ribonucleotide reductase $\mathrm{M1}$}

Ribonucleotide reductase M1 (RRM1) is part of the enzyme ribonucleotide reductase, which plays a vital role in the production of deoxyribonucleotides prior to DNA synthesis in dividing cells [36]. ZHENG et al. [37] reported on 187 NSCLC stage IB patients who received neo-ACT before surgery. Low RRM1 expression was associated with a worse prognosis compared with patients with high RRM1 expression regarding both OS and progression-free survival (PFS). Median OS for patients with low and high RRM1 expression was 54.5 months and 120.0 months, respectively ( $\mathrm{p}=0.002$ ). Low RRM1 status was defined by ZHENG et al. [37] as less than the median gene expression score. Similar results were presented in 2012 by PESTA et al. [17] in an adjuvant setting on a much smaller group of NSCLC patients in stages I-III. Differences in DFS and OS were only observed in specific subgroups such as squamous cell carcinoma (SCC) or adenocarcinoma and stage III, with low expression of RRM1 associated with worse DFS ( $p=0.033$ ) and OS ( $p=0.033)$. PESTA et al. [17] found the optimal cut-off value for low RRM1 in the most statistically significant results (with the lowest p-values) of maximum likelihood estimates analysis.

\section{Excision repair cross-complementation group 1}

Excision repair cross-complementation group 1 (ERCC1) is an enzyme that forms part of the nucleotide excision repair pathway and is involved in the repair of DNA damage, especially cisplatin-induced damage $[18,38]$. One of the first articles on ERCC1 and its possible prognostic and predictive value was published by Olaussen et al. [18] in 2006. They found that high expression of ERCC1 was associated with better OS (HR 0.66, 95\% CI 0.49-0.90; $\mathrm{p}=0.009)$. High ERCC1 status was defined as the median value or above $(\geqslant 2$; score range: 0-3) [18]. PIERCEALl et al. [21] reported, based solely on 426 patients with SCC histology, that high expression (defined as greater than the median Q-score value) was associated with better DFS (HR 0.66, 95\% CI 0.45-0.96; $\mathrm{p}=0.03$ ), but not OS (HR 0.71, 95\% CI 0.48-1.03; $\mathrm{p}=0.15$ ), compared with patients with low expression. PESTA et al. [17] reported a similar result in a much smaller group of SCC patients, while three other articles reported the opposite, with low ERCC1 expression associated with significantly better DFS and OS [16, 19, 20]. OKUDA et al. [16] found that high expression of ERCC1 (high $\geqslant 1$; score range: $0-1$ ) was associated with worse OS (HR 2.18, 95\% CI 1.16-4.01; $\mathrm{p}=0.0145$ ). A recent article by FRIBOULET et al. [39] revealed that the optimal antibody for examination of ERCC1 expression has yet to be found, which could explain the variability in results.

\section{Breast cancer type 1 susceptibility protein}

Breast cancer type 1 susceptibility protein (BRCA1) contributes to the repair of double-strand breaks in the DNA [40] and also functions as a regulator of chemotherapy-induced apoptosis [41]. High BRCA1 expression in completely resected NSCLC patients was associated with poor prognosis with the median OS for high versus low expression being 29 months versus not reached ( $\mathrm{p}=0.01)$ [42]. Rosell et al. [42] used the minimum p-value method to define mRNA gene expression levels as high or low. By contrast, PESTA et al. [17] reported high BRCA1 to be associated with longer OS in a small patient group receiving ACT ( $p=0.03)$. 


\begin{tabular}{|c|c|c|c|c|c|c|c|c|c|c|c|c|}
\hline \multirow{3}{*}{$\begin{array}{l}\text { First author } \\
\text { [ref.] }\end{array}$} & \multirow[t]{3}{*}{ Subjects $\mathrm{n}$} & \multirow[t]{3}{*}{ Treatment } & \multirow[t]{3}{*}{ Stage } & \multirow[t]{3}{*}{ Method } & \multirow[t]{3}{*}{ Biomarker } & \multirow{3}{*}{$\begin{array}{l}\text { Biomarker } \\
\text { expression }\end{array}$} & \multicolumn{3}{|c|}{ Disease-free survival } & \multicolumn{3}{|c|}{ Overall survival } \\
\hline & & & & & & & \multirow[t]{2}{*}{ Survival } & \multicolumn{2}{|c|}{$\mathrm{p}$-value } & \multirow[t]{2}{*}{ Survival } & \multicolumn{2}{|c|}{ p-value } \\
\hline & & & & & & & & Univariate & Multivariate & & Univariate & Multivariate \\
\hline ILIE [13] & $\begin{array}{l}\text { 632, only } \\
\text { SCC }\end{array}$ & $\begin{array}{c}\text { ACT (type: NA) } \\
\text { or OP }\end{array}$ & $|-| I \mid$ & $\mathrm{IHC}$ & iNTR & $\begin{array}{l}\text { Low } \\
\text { High }\end{array}$ & $\begin{array}{l}43 \text { months } \\
34 \text { months }\end{array}$ & $<0.0001$ & NA & $\begin{array}{l}60 \text { months } \\
46 \text { months }\end{array}$ & $<0.0001$ & NA \\
\hline \multirow[t]{2}{*}{ SĖVE [14] } & 265 & $\begin{aligned} & \text { ACT (CDDP } \\
+ & \text { NVB) or OPा }\end{aligned}$ & $|\mathrm{B}-| \mid$ & $\mathrm{IHC}$ & TUBB3 & High & $\begin{array}{l}\text { HR: } 1.52 \\
(1.05-2.22)\end{array}$ & 0.03 & 0.03 & $\begin{array}{l}\text { HR: } 1.39 \\
(0.96-2.01)\end{array}$ & 0.08 & 0.07 \\
\hline & & & & & & Low & NA & NA & NA & NA & NA & NA \\
\hline \multirow[t]{2}{*}{ ReIman [15] } & 1149 & $\begin{aligned} & \text { ACT (CDDP } \\
+ & \text { NVB) or OPף }\end{aligned}$ & $|-|||$ & $\mathrm{IHC}$ & TUBB3 & High & $\begin{array}{l}\text { HR: } 1.30 \\
(1.11-1.53)\end{array}$ & NA & 0.001 & $\begin{array}{l}\text { HR: } 1.27 \\
(1.07-1.51)\end{array}$ & NA & 0.008 \\
\hline & & & & & & Low & 1 (reference) & NA & & 1 (reference) & NA & \\
\hline \multirow[t]{2}{*}{ ОKUDA [16] } & 50 & АCT (CDDP- & $|-|||$ & IHC & TUBB3 & Positive & NA & NA & NA & $27 \%$ & 0.0303 & NA \\
\hline & & based) or OP\# & & & & Negative & NA & NA & NA & $74.6 \%$ & NA & \\
\hline \multirow[t]{2}{*}{ Pesta [17] } & 22 , only & ACT & $|-|||$ & RT-PCR & RRM1 & High & NA & NA & NA & 803 days & NA & 0.033 \\
\hline & $A D C$ & $\begin{array}{l}\text { (platinum- } \\
\text { based) or OP\# }\end{array}$ & & & & Low & NA & NA & NA & 386 days & NA & \\
\hline \multirow[t]{2}{*}{ Pesta [17] } & 16 & ACT Iplatinum- & III & RT-PCR & RRM1 & High & 643 days & NA & 0.033 & NA & NA & NA \\
\hline & & based) or OP\# & & & & Low & 144 days & NA & & NA & NA & NA \\
\hline \multirow[t]{2}{*}{ OLaussen [18] } & 761 & $\begin{array}{l}\text { ACT (CDDP- } \\
\text { based) or OPी }\end{array}$ & $|-|||$ & IHC & ERCC1 & High & NA & NA & NA & $\begin{array}{l}\text { HR: } 0.66 \\
(0.49-0.90)\end{array}$ & NA & 0.009 \\
\hline & & & & & & Low & NA & NA & NA & 1 (reference) & NA & \\
\hline \multirow[t]{2}{*}{ Pesta [17] } & 14 , only & ACT Iplatinum- & III & RT-PCR & ERCC1 & High & 337 days & NA & 0.044 & NA & NA & NA \\
\hline & SCC & based) or OP & & & & Low & 128 days & NA & & NA & NA & NA \\
\hline Leng [19] & 85 & $\begin{array}{l}\mathrm{ACT} \text { (platinum- } \\
\text { based) }^{+}\end{array}$ & I-IV & PCR & ERCC1 & $\begin{array}{l}\text { Low } \\
\text { High }\end{array}$ & $\begin{array}{l}>42.6 \text { months } \\
15.4 \text { months }\end{array}$ & 0.001 & 0.018 & $\begin{array}{l}>42.6 \text { months } \\
20.9 \text { months }\end{array}$ & 0.001 & 0.027 \\
\hline Cивикси [20] & 44 & $\begin{array}{l}\text { ACT (platinum- } \\
\text { based) }^{+}\end{array}$ & $|-||| B$ & $\mathrm{IHC}$ & ERCC1 & $\begin{array}{l}\text { Low } \\
\text { High }\end{array}$ & $\begin{array}{l}27 \text { months } \\
13 \text { months }\end{array}$ & $<0.05$ & $<0.05$ & $\begin{array}{l}33 \text { months } \\
20 \text { months }\end{array}$ & $<0.05$ & $<0.05$ \\
\hline \multirow[t]{2}{*}{ Pierceall [21] } & $\begin{array}{l}\text { 426, only } \\
\text { SCC }\end{array}$ & $\begin{array}{l}\text { ACT (CDDP- } \\
\text { based) or OPी }\end{array}$ & $|-|||$ & $\mathrm{IHC}$ & ERCC1 & High & $\begin{array}{l}\text { HR: } 0.66 \\
(0.45-0.96)\end{array}$ & 0.01 & 0.03 & $\begin{array}{l}\text { HR: } 0.71 \\
(0.48-1.03)\end{array}$ & 0.07 & 0.15 \\
\hline & & & & & & Low & 1 (reference) & & & 1 (reference) & & \\
\hline \multirow[t]{2}{*}{ ОKUDA [16] } & 90 & ACT ICDDP- & I-III & IHC & ERCC1 & Positive & NA & NA & NA & $37.6 \%$ & 0.0068 & NA \\
\hline & & basedl or $\mathrm{OP}^{\#}$ & & & & Negative & NA & NA & NA & $\begin{array}{c}60.8 \% \\
\text { HR: } 2.18 \\
(1.16-4.01)\end{array}$ & 0.0145 & NA \\
\hline Pesta [17] & 10 & $\begin{array}{l}\text { ACT (platinum- } \\
\text { based) or OP\# }\end{array}$ & I & RT-PCR & BRCA1 & High & NA & NA & NA & Longer OS & NA & 0.03 \\
\hline \multirow[t]{2}{*}{ GraZIANo [22] } & 250 & $\begin{array}{l}\text { ACT (CBDCA + } \\
\text { Pacl) or OPף }\end{array}$ & IB & $\mathrm{IHC}$ & p53 & Positive & $\begin{array}{l}\text { HR: } 1.95 \\
(1.26-3.02)\end{array}$ & NA & 0.0029 & $\begin{array}{l}\text { HR: } 2.30 \\
(1.44-3.67)\end{array}$ & NA & 0.0005 \\
\hline & & & & & & Negative & 1 (reference) & NA & & 1 (reference) & NA & \\
\hline \multirow[t]{2}{*}{ Pierceall [21] } & $\begin{array}{l}\text { 426, only } \\
\text { SCC }\end{array}$ & $\begin{array}{l}\text { ACT (CDDP- } \\
\text { based) or OPI }\end{array}$ & $|-| I \mid$ & IHC & p53 & High & $\begin{array}{l}\text { HR: } 0.72 \\
\text { (0.5-1.03) }\end{array}$ & NA & 0.08 & $\begin{array}{c}\text { HR: } 0.69 \\
(0.48-1.00)\end{array}$ & 0.03 & 0.05 \\
\hline & & & & & & Low & 1 (reference) & NA & & 1 (reference) & & \\
\hline TSAO [23] & 253 & $\begin{array}{l}\text { ACT (CDDP- } \\
\text { NVB) or OPף }\end{array}$ & |B-I| & $\mathrm{IHC}$ & p53 & Positive & NA & NA & NA & $\begin{array}{c}\text { HR: } 1.89 \\
(1.07-3.34)\end{array}$ & 0.03 & 0.02 \\
\hline & & & & & & Negative & NA & NA & NA & 1 (reference) & & \\
\hline
\end{tabular}




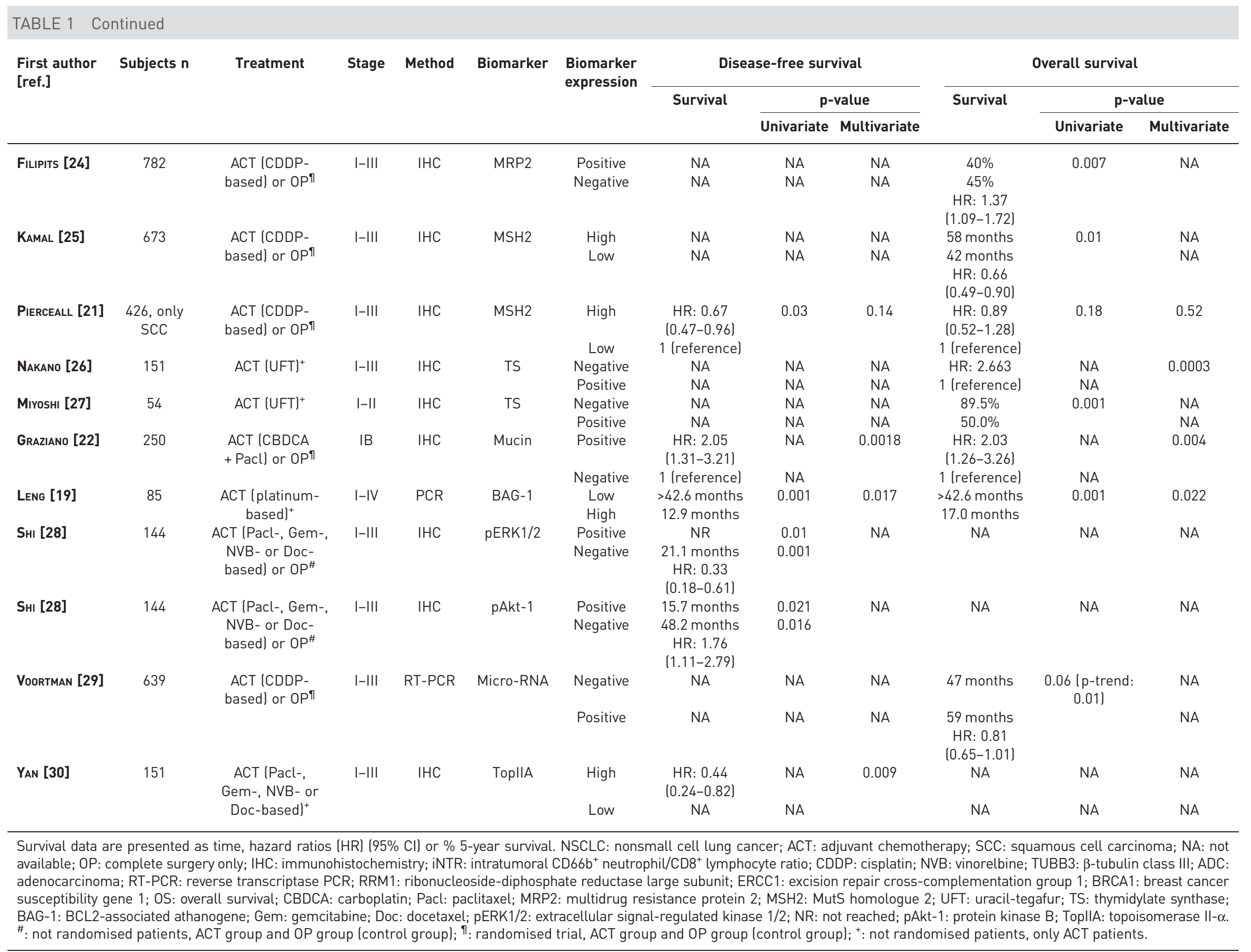


TABLE 2 Prognostic impact of biomarker gene signatures in NSCLC patients treated with complete resection with or without ACT

\begin{tabular}{|c|c|c|c|c|c|c|c|c|c|c|c|c|}
\hline \multirow{3}{*}{$\begin{array}{l}\text { First } \\
\text { author } \\
\text { [ref.] }\end{array}$} & \multirow[t]{3}{*}{ Subjects $n$} & \multirow[t]{3}{*}{ Treatment } & \multirow[t]{3}{*}{ Stage } & \multirow[t]{3}{*}{ Method } & \multirow[t]{3}{*}{ Biomarker } & \multirow{3}{*}{$\begin{array}{l}\text { Biomarker } \\
\text { expression }\end{array}$} & \multicolumn{3}{|c|}{ Disease-free survival } & \multicolumn{3}{|c|}{ Overall survival } \\
\hline & & & & & & & \multirow[t]{2}{*}{ Survival } & \multicolumn{2}{|c|}{ p-value } & \multirow[t]{2}{*}{ Survival } & \multicolumn{2}{|c|}{ p-value } \\
\hline & & & & & & & & Univariate & Multivariate & & Univariate & Multivariate \\
\hline \multirow[t]{2}{*}{ Zно [31] } & 133 & $\begin{array}{l}\text { ACT (CDDP + } \\
\text { NVB) or OP }\end{array}$ & IB-II & RT-PCR & $\begin{array}{l}\text { 15-gene } \\
\text { signature }\end{array}$ & High risk & NA & NA & NA & $\begin{array}{l}\text { HR: } 15.02 \\
(5.12-44.04)\end{array}$ & $<0.01$ & NA \\
\hline & & & & & & Low risk & NA & NA & NA & NA & NA & NA \\
\hline \multirow[t]{2}{*}{ Chen [32] } & 62 & $\mathrm{OP}$ & |-III & DNA & 92-gene & High risk & NA & NA & NA & $39.2 \%$ & 0.01 & NA \\
\hline & & & & microarray & signature & Low risk & NA & NA & NA & $71.4 \%$ & & NA \\
\hline \multirow[t]{3}{*}{ KRATZ [33] } & 967 only & $\mathrm{OP}$ & |-III & qPCR & 14-gene & High risk & NA & NA & NA & $44.6 \%$ & $<0.0001$ & NA \\
\hline & non-SCC & & & & signature & $\begin{array}{l}\text { Intermediate } \\
\text { risk }\end{array}$ & NA & NA & NA & $57.4 \%$ & & NA \\
\hline & & & & & & Low risk & NA & NA & NA & $74.1 \%$ & & \\
\hline \multirow[t]{2}{*}{$\begin{array}{l}\text { Wistuba } \\
\text { [34] }\end{array}$} & 381 & $\mathrm{OP}$ & $\begin{array}{l}\text { IA- } \\
\text { IIB }\end{array}$ & qPCR & $\begin{array}{l}\text { 31-gene } \\
\text { signature }\end{array}$ & High CCP score & $\begin{array}{l}\text { HR: } 2.10 \\
(1.39-3.17)\end{array}$ & 0.00033 & NA & $\begin{array}{l}\text { HR: } 1.92 \\
(1.18-3.10)\end{array}$ & 0.0071 & NA \\
\hline & & & & & & Low CCP score & & & NA & & & NA \\
\hline
\end{tabular}

Survival data are presented as hazard ratios (HR) $(95 \%$ CI) or \% 5-year survival. NSCLC: nonsmall cell lung cancer; ACT: adjuvant chemotherapy; CDDP: cisplatin; NVB: vinorelbine; OP: complete surgery only; RT-PCR: reverse transcriptase PCR; NA: not available; SCC: squamous cell carcinoma; qPCR: quantitative PCR; CCP: cell cycle progression gene. : randomised trial, ACT group and OP group (control group). 
PESTA et al. [17] found the optimal cut-off value for high BRCA1 in a similar way, using the cut-off yielding the most statistically significant results.

p53

p53 is a protein encoded by the TP53 gene and plays a key role in tumour suppression and in the cellular response to DNA damage [43]. Two studies presented similar data on the prognostic role of p53 in completely resected NSCLC patients (stage IB-II) receiving ACT [22, 23]. Both studies reported that positive p53 status was associated with worse outcome: DFS HR 1.95 (95\% CI 1.26-3.02; p=0.0029) and OS HR 2.30 (95\% CI 1.44-3.67; p=0.005) [22], and OS HR 1.89 (95\% CI 1.07-3.34; p=0.02) [23]. Positive p53 status was defined by Graziano et al. [22] as a score $\geqslant 2$ (score range: $0-4$ ) and by TsaO et al. [23] as a score $\geqslant 1$ (score range: $0-3$ ). By contrast, PierCeall et al. [21] presented data solely from squamous cell histology NSCLC patients (stage I-III) and observed high p53 expression (high defined as greater than the median Q-score) to be associated with better outcome than low expression, with respect to both DFS (HR 0.73, 95\% CI 0.5-1.03; $\mathrm{p}=0.08$ ) and OS (HR 0.69, 95\% CI 0.48-1.00; $\mathrm{p}=0.05$ ).

\section{Multidrug resistance protein 2}

Multidrug resistance protein 2 (MRP2) is an ATP-binding cassette transport protein. Overexpression of MRP2 in tumour cells confers resistance to various anticancer drugs, including anthracyclines, vinca alkaloids and cisplatin [44]. FILIPITs et al. [24] reported patients with negative MRP2 status (negative defined as less than the median staining score; score range: $0-3$ ) to have a $45 \% 5$-year survival, compared with $40 \%$ in MRP2-positive patients ( $\mathrm{p}=0.007)$.

\section{MutS homologue 2}

MutS homologue 2 (MSH2) is a gene that is crucially involved in the repair of cisplatin-DNA cross-links. MSH2 binds to DNA mismatches, thereby initiating DNA repair. In addition to its function in the mismatch repair pathway, MSH2 also recognises and binds to cisplatin-induced DNA interstrand cross-links, thereby initiating their excision and repair [45, 46]. Kamal et al. [25] reported patients with high expression of MSH2 (high: 3; score range: 0-3) to have better OS than patients with low expression (HR 0.66, 95\% CI 0.49-0.90; $\mathrm{p}=0.01$ ). Pierceall et al. [21] also found high MSH2 (high defined as greater than the median Q-score) to be associated with longer DFS (HR 0.67, 95\% CI 0.47-0.96; p=0.03), but not with OS.

\section{Thymidylate synthase}

Thymidylate synthase is an enzyme used to generate thymidine monophosphate, which is subsequently phosphorylated to thymidine triphosphate for use in DNA synthesis and repair [47]. There are two contradicting studies reporting on thymidylate synthase expression. NAKANO et al. [26] observed that patients (stage I-III) with low thymidylate synthase expression (low was defined as <30; H-score range:

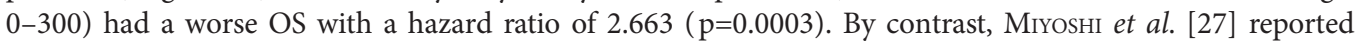
that thymidylate synthase negative patients (stage I-II) had an 89\% 5-year survival rate, unlike thymidylate synthase positive patients who had 50\% 5-year survival $(\mathrm{p}=0.001)$. MrYoshi et al. [27] defined negative thymidylate synthase status as $<10 \%$ positively stained cancer cells.

\section{BCL2-associated athanogene}

BCL2-associated athanogene (BAG-1) is a multifunctional binding protein involved in differentiation, the cell cycle and apoptosis. BAG-1 inhibits apoptosis by binding to and interacting with the anti-apoptotic protein BCL-2 [48]. Another study observed that BAG-1 could be a target for lung cancer treatment with cisplatin [49]. In 2012, LENG et al. [19] reported that low BAG-1 expression (cut-off unknown) was associated with better OS in a group of NSCLC patients treated with platinum-based ACT compared with patients with high expression $(\mathrm{p}=0.022)$.

\section{Topoisomerase $/ 1-\alpha$}

Topoisomerase II- $\alpha$ is a nuclear enzyme that catalyses the conversion between DNA topological isomers and can be detected in cells with high proliferative activity. Many anticancer agents exert their anticancer effects by stabilising DNA cleavage and inhibiting DNA replication via binding and blocking the activity of topoisomerase II- $\alpha$ [50]. High topoisomerase II- $\alpha$ expression (high was defined as $\geqslant 2$; score range: $0-3$ ) has been associated with better DFS (HR 0.44, 95\% CI 0.24-0.82; $\mathrm{p}=0.009$ ) [30]. 
(HR 15.02, 95\% CI 5.12-44.0; $\mathrm{p}<0.01$ ). It was also observed that this 15 -gene signature was predictive for outcome when administering ACT; these results are described in the section on predictive biomarkers.

31-gene signature

In 2013, WistuBA et al. [34] presented results on a gene profile including 31 cell cycle progression genes (CCP score). Low CCP score (cut-off: median CCP score) was associated with better cancer-specific survival in a population of 381 surgically treated NSCLC patients with stage IA-IIB. Patients with high CCP score had a univariate hazard ratio of $2.10(95 \%$ CI $1.39-3.17 ; \mathrm{p}<0.01)$ and a multivariate hazard ratio of 1.92 (95\% CI 1.18-3.10; $\mathrm{p}<0.01)$.

Results on mucin, extracellular signal-regulated kinase 1/2 (pERK1/2), protein kinase B (pAkt-1), microRNA, a 92-gene signature and a prognostic 14-gene signature are also presented in tables 1 and 2.

\section{Predictive biomarkers}

Data for predictive biomarkers are shown in tables 3 and 4 .

\section{ERCC1}

Olaussen et al. [18] presented data showing low ERCC1 expression (low was defined as a score $<2$; score range: $0-3)$ to be predictive of benefits from cisplatin-based ACT. The patient group with low ERCC1 expression and who were treated with ACT had a median OS of 56 months versus 42 months in patients with low ERCC1 status that did not receive ACT $(\mathrm{p}=0.002)$. There was no significant difference in the high expression group. In a study by BEPLER et al. [51], low expression of ERCC1 (low was defined as $<10$, median 9; range: $2.2-149.1$ ) was also associated with better DFS (HR 0.76, 95\% CI 0.59-0.99; $\mathrm{p}=0.04$ ) and OS (HR 0.73, 95\% CI 0.55-0.96; $\mathrm{p}=0.02$ ) when comparing the ACT group with the control group.

p53

TsAo et al. [23] presented data from 253 patients with stage IB-II NSCLC receiving ACT or complete resection only (control group). Positive p53 status (positive was defined as $>15 \%$ of final staining score) was predictive of better OS (HR 0.54, 95\% CI 0.32-0.92; $\mathrm{p}=0.05$ ), when comparing the positive ACT group with the positive control group. Comparing the two p53-negative groups (ACT versus control group) with each other yielded a hazard ratio of 1.4 (95\% CI 0.78-2.52; $\mathrm{p}=0.26)$. However, PierCEAlL et al. [21] observed that ACT versus control with high p53 expression (high was defined as greater than the median Q-score) predicted poor DFS and OS. Both studies used immunohistochemistry (IHC) to examine p53 status/expression and used cisplatin-based ACT. The results of PIERCEALl et al. [21] were based solely on patients with squamous histology (stage I-III) while data from the study by Tsao et al. [23] were based on all histological types (stage IB-II).

\section{MSH2}

Low MSH2 (low H-score was defined as <3, median 2; range: 0-3) status has been predictive for a better OS when comparing ACT versus controls (HR 0.76, 95\% CI 0.59-0.97; $\mathrm{p}=0.03$ ) in one study [25]. Another study comparing patients that had received chemotherapy with controls, both having high MSH2 (high was defined as greater than the median Q-score), showed that high MSH2 was associated with poor DFS (HR 1.71, 95\% CI 1.03-2.87; p=0.04) [21].

\section{Cyclin-dependent kinase inhibitor $1 B$}

Cyclin-dependent kinase inhibitor 1B (p27 (kip1)) is an enzyme inhibitor that is often referred to as a cell cycle inhibitor protein because its major function is to stop or slow down the cell division cycle in the G1 phase [54]. Data from the International Adjuvant Lung cancer Trial (IALT) [52] showed that patients with p27 (kip1)-negative tumours (negative was defined as less than the median H-score; score range: 0-300) treated with cisplatin-based ACT had longer OS compared with controls (HR 0.66, 95\% CI 0.50-0.88; $\mathrm{p}=0.006$ ). For patients with $\mathrm{p} 27$ (kip1)-positive tumours there was no difference in OS between patients treated with cisplatin-based chemotherapy and controls (HR 1.09, 95\% CI 0.82-1.45; p=0.54) [52].

\section{TUBB3}

High expression of TUBB3 (high was defined as greater than the median H-score) predicted significantly longer DFS in patients treated with cisplatin-based ACT compared with controls (HR 0.45, 95\% CI 0.27 0.75; $\mathrm{p}=0.002$ ) and nearly reached significance for better OS (HR 0.64, 95\% CI 0.39-1.04; $\mathrm{p}=0.07$ ) [14]. 


\begin{tabular}{|c|c|c|c|c|c|c|c|c|c|c|c|c|}
\hline \multirow{3}{*}{$\begin{array}{l}\text { First author } \\
\text { [ref.] }\end{array}$} & \multirow{3}{*}{$\begin{array}{c}\text { Subjects } \\
n\end{array}$} & \multirow[t]{3}{*}{ Treatment } & \multirow[t]{3}{*}{ Stage } & \multirow[t]{3}{*}{ Method } & \multirow[t]{3}{*}{ Biomarker } & \multirow{3}{*}{$\begin{array}{l}\text { Biomarker } \\
\text { expression }\end{array}$} & \multicolumn{3}{|c|}{ Disease-free survival } & \multicolumn{3}{|c|}{ Overall survival } \\
\hline & & & & & & & \multirow[t]{2}{*}{ Survival } & \multicolumn{2}{|c|}{ p-value } & \multirow[t]{2}{*}{ Survival } & \multicolumn{2}{|c|}{ p-value } \\
\hline & & & & & & & & Univariate & Multivariate & & Univariate & Multivariate \\
\hline \multirow[t]{2}{*}{ BepLeR [51] } & 784 & $\begin{array}{l}\text { ACT (CDDP- } \\
\text { based) or OP\# }\end{array}$ & $|-|||$ & $\mathrm{IHC}$ & ERCC1 & $\begin{array}{l}\text { Low (ACT } \\
\text { versus OP) }\end{array}$ & $\begin{array}{l}\text { HR: } 0.76 \\
(0.59-0.99)\end{array}$ & 0.04 & NA & $\begin{array}{l}\text { HR: } 0.73 \\
(0.55-0.96)\end{array}$ & 0.02 & NA \\
\hline & & & & & & $\begin{array}{l}\text { High (ACT } \\
\text { versus } \mathrm{OP} \text { ) }\end{array}$ & $\begin{array}{l}\text { HR: } 0.97 \\
(0.72-1.30)\end{array}$ & 0.82 & NA & $\begin{array}{l}\text { HR: } 1.01 \\
(0.74-1.38)\end{array}$ & 0.94 & NA \\
\hline \multirow[t]{2}{*}{ Olaussen [18] } & 761 & $\begin{array}{l}\text { ACT (CDDP- } \\
\text { based) or OP\# }\end{array}$ & |-III & $\mathrm{IHC}$ & ERCC1 & $\begin{array}{l}\text { Low (ACT } \\
\text { versus OP) }\end{array}$ & NA & 0.001 & NA & $\begin{array}{l}56 \text { versus } \\
42 \text { months }\end{array}$ & 0.002 & NA \\
\hline & & & & & & $\begin{array}{l}\text { High (ACT } \\
\text { versus } \mathrm{OP} \text { ) }\end{array}$ & NA & & NA & $\begin{array}{l}50 \text { versus } \\
55 \text { months }\end{array}$ & 0.40 & NA \\
\hline \multirow[t]{2}{*}{ Pierceall [21] } & $\begin{array}{l}426 \text { only } \\
\text { SCC }\end{array}$ & $\begin{array}{l}\text { ACT (CDDP- } \\
\text { based) or OP }\end{array}$ & $|-|||$ & $\mathrm{IHC}$ & ERCC1 & $\begin{array}{l}\text { High (ACT } \\
\text { versus OP) }\end{array}$ & $\begin{array}{c}\text { HR: } 2.02 \\
(1.19-3.43)\end{array}$ & NA & 0.01 & $\begin{array}{l}\text { HR: } 1.67 \\
(0.97-2.87)\end{array}$ & NA & 0.06 \\
\hline & & & & & & $\begin{array}{l}\text { Low (ACT } \\
\text { versus OP) }\end{array}$ & NA & NA & & NA & NA & \\
\hline \multirow[t]{2}{*}{ TsAo [23] } & 253 & $\begin{array}{l}\text { ACT (CDDP + } \\
\text { NVB) or OP\# }\end{array}$ & IB-II & $\mathrm{IHC}$ & p53 & $\begin{array}{c}\text { Positive (ACT } \\
\text { versus } \mathrm{OP} \text { ) }\end{array}$ & NA & NA & NA & $\begin{array}{l}\text { HR: } 0.54 \\
(0.32-0.92)\end{array}$ & 0.02 & 0.05 \\
\hline & & & & & & $\begin{array}{c}\text { Negative } \\
\text { (ACT versus } \\
\text { OP) }\end{array}$ & NA & NA & NA & $\begin{array}{c}\text { HR: } 1.4 \\
(0.78-2.52)\end{array}$ & 0.26 & NA \\
\hline \multirow[t]{2}{*}{ Pierceall [21] } & $\begin{array}{l}426 \text { only } \\
\text { SCC }\end{array}$ & $\begin{array}{l}\text { ACT (CDDP- } \\
\text { based) or OP\# }\end{array}$ & $|-|||$ & $\mathrm{IHC}$ & p53 & $\begin{array}{l}\text { High (ACT } \\
\text { versus OP) }\end{array}$ & $\begin{array}{c}\text { HR: } 1.72 \\
\text { (1.03-2.88) }\end{array}$ & NA & 0.04 & $\begin{array}{c}\text { HR: } 1.81 \\
(1.07-3.06)\end{array}$ & NA & 0.03 \\
\hline & & & & & & $\begin{array}{l}\text { Low (ACT } \\
\text { versus OP) }\end{array}$ & NA & NA & & NA & NA & \\
\hline \multirow[t]{2}{*}{ Pierceall [21] } & $\begin{array}{l}426 \text { only } \\
\text { SCC }\end{array}$ & $\begin{array}{l}\text { ACT (CDDP- } \\
\text { based) or OP\# }\end{array}$ & $|-|||$ & $\mathrm{IHC}$ & MSH2 & $\begin{array}{l}\text { High (ACT } \\
\text { versus } \mathrm{OP} \text { ) }\end{array}$ & $\begin{array}{l}\text { HR: } 1.72 \\
(1.03-2.87)\end{array}$ & NA & 0.04 & $\begin{array}{l}\text { HR: } 1.37 \\
(0.82-2.30)\end{array}$ & NA & 0.24 \\
\hline & & & & & & $\begin{array}{l}\text { Low (ACT } \\
\text { versus OP) }\end{array}$ & NA & NA & & NA & NA & \\
\hline \multirow[t]{2}{*}{ KamaL [25] } & 673 & $\begin{array}{l}\text { ACT (CDDP- } \\
\text { based) or OP\# }\end{array}$ & $|-|||$ & $\mathrm{IHC}$ & MSH2 & $\begin{array}{l}\text { Low (ACT } \\
\text { versus OP) }\end{array}$ & NA & NA & NA & $\begin{array}{l}\text { HR: } 0.76 \\
(0.59-0.97)\end{array}$ & 0.03 & NA \\
\hline & & & & & & $\begin{array}{l}\text { High (ACT } \\
\text { versus OP) }\end{array}$ & NA & NA & NA & $\begin{array}{l}\text { HR: } 1.12 \\
(0.81-1.55)\end{array}$ & 0.48 & NA \\
\hline \multirow[t]{2}{*}{ KamAL [25] } & 673 & $\begin{array}{l}\text { ACT (CDDP- } \\
\text { based) or OP\# }\end{array}$ & $|-|||$ & $\mathrm{IHC}$ & $\begin{array}{c}\text { ERCC1 + } \\
\text { MSH2 }\end{array}$ & $\begin{array}{l}\text { Low-low } \\
\text { (ACT versus } \\
\text { OP) }\end{array}$ & NA & NA & NA & $\begin{array}{l}\text { HR: } 0.65 \\
(0.47-0.91)\end{array}$ & 0.01 & NA \\
\hline & & & & & & $\begin{array}{l}\text { High-high } \\
\text { (ACT versus } \\
\text { OP) }\end{array}$ & NA & NA & NA & $\begin{array}{l}\text { HR: } 1.32 \\
(0.88-1.99)\end{array}$ & 0.19 & NA \\
\hline \multirow[t]{2}{*}{ KamAL [25] } & 673 & $\begin{array}{l}\text { ACT (CDDP- } \\
\text { based) or OP\# }\end{array}$ & $|-|||$ & $\mathrm{IHC}$ & $\begin{array}{l}\text { p27 (kip1) } \\
+\mathrm{MSH} 2\end{array}$ & $\begin{array}{l}\text { Low-low } \\
\text { (ACT versus } \\
\text { OP) }\end{array}$ & NA & NA & NA & $\begin{array}{l}\text { HR: } 0.65 \\
(0.46-0.93)\end{array}$ & 0.01 & NA \\
\hline & & & & & & $\begin{array}{l}\text { High-high } \\
\text { (ACT versus } \\
\text { OP) }\end{array}$ & NA & NA & NA & $\begin{array}{l}\text { HR: } 1.31 \\
(0.85-2.01)\end{array}$ & 0.22 & NA \\
\hline
\end{tabular}




\begin{tabular}{|c|c|c|c|c|c|c|c|c|c|c|c|c|}
\hline \multirow{3}{*}{$\begin{array}{l}\text { First author } \\
\text { [ref.] }\end{array}$} & \multirow{3}{*}{$\begin{array}{c}\text { Subjects } \\
n\end{array}$} & \multirow[t]{3}{*}{ Treatment } & \multirow[t]{3}{*}{ Stage } & \multirow[t]{3}{*}{ Method } & \multirow[t]{3}{*}{ Biomarker } & \multirow{3}{*}{$\begin{array}{l}\text { Biomarker } \\
\text { expression }\end{array}$} & \multicolumn{3}{|c|}{ Disease-free survival } & \multicolumn{3}{|c|}{ Overall survival } \\
\hline & & & & & & & \multirow[t]{2}{*}{ Survival } & \multicolumn{2}{|c|}{$\mathrm{p}$-value } & \multirow[t]{2}{*}{ Survival } & \multicolumn{2}{|c|}{ p-value } \\
\hline & & & & & & & & Univariate & Multivariate & & Univariate & Multivariate \\
\hline \multirow[t]{2}{*}{ FILIPITS [52] } & 778 & $\begin{array}{l}\text { ACT (CDDP- } \\
\text { based) or OP" }\end{array}$ & $|-|||$ & $\mathrm{IHC}$ & p27 (kip1) & $\begin{array}{c}\text { Negative } \\
\text { (ACT versus } \\
\text { OP) }\end{array}$ & $\begin{array}{l}\text { HR: } 0.71 \\
(0.54-0.94)\end{array}$ & 0.02 & NA & $\begin{array}{l}\text { HR: } 0.66 \\
(0.5-0.88)\end{array}$ & 0.006 & NA \\
\hline & & & & & & $\begin{array}{c}\text { Positive (ACT } \\
\text { versus OP) }\end{array}$ & NA & & NA & $\begin{array}{l}\text { HR: } 1.09 \\
(0.82-1.45)\end{array}$ & 0.54 & NA \\
\hline \multirow[t]{2}{*}{ SÈVE [14] } & 265 & $\begin{aligned} & \text { ACT (CDDP } \\
+ & \text { NVB) or OP\# }\end{aligned}$ & $|B-| \mid$ & $\mathrm{IHC}$ & TUBB3 & $\begin{array}{l}\text { High (ACT } \\
\text { versus OP) }\end{array}$ & $\begin{array}{c}\text { HR: } 0.45 \\
(0.27-0.75)\end{array}$ & 0.002 & NA & $\begin{array}{c}\text { HR: } 0.64 \\
(0.39-1.04)\end{array}$ & 0.07 & NA \\
\hline & & & & & & $\begin{array}{l}\text { Low (ACT } \\
\text { versus OP) }\end{array}$ & $\begin{array}{l}\text { HR: } 0.78 \\
(0.44-1.37)\end{array}$ & 0.4 & NA & $\begin{array}{l}\text { HR: } 1.00 \\
(0.57-1.75)\end{array}$ & 0.99 & NA \\
\hline \multirow[t]{2}{*}{ Pierceall [21] } & $\begin{array}{l}426 \text { only } \\
\text { SCC }\end{array}$ & $\begin{array}{l}\text { ACT (CDDP- } \\
\text { based) or OP }\end{array}$ & $|-|||$ & $\mathrm{IHC}$ & PARP1 & $\begin{array}{l}\text { High (ACT } \\
\text { versus } \mathrm{OP})\end{array}$ & $\begin{array}{l}\text { HR: } 1.74 \\
(1.04-2.91)\end{array}$ & NA & 0.04 & $\begin{array}{c}\text { HR: } 1.63 \\
(0.96-2.75)\end{array}$ & NA & 0.07 \\
\hline & & & & & & $\begin{array}{l}\text { Low (ACT } \\
\text { versus OP) }\end{array}$ & NA & NA & & NA & NA & \\
\hline \multirow[t]{2}{*}{ Pierceall [21] } & $\begin{array}{l}426 \text { only } \\
\text { SCC }\end{array}$ & $\begin{array}{l}\text { ACT (CDDP- } \\
\text { based) or OP\# }\end{array}$ & $|-|||$ & $\mathrm{IHC}$ & ATM & $\begin{array}{l}\text { High (ACT } \\
\text { versus OP) }\end{array}$ & $\begin{array}{l}\text { HR: } 2.08 \\
(1.24-3.49)\end{array}$ & NA & 0.005 & $\begin{array}{l}\text { HR: } 1.82 \\
(1.07-3.07)\end{array}$ & NA & 0.03 \\
\hline & & & & & & $\begin{array}{l}\text { Low (ACT } \\
\text { versus OP) }\end{array}$ & NA & NA & & NA & NA & \\
\hline $\begin{array}{l}\text { Survival data } \\
\text { immunohistoch } \\
\text { (kip1): cyclin-d } \\
\text { group (control }\end{array}$ & $\begin{array}{l}\text { resented a } \\
\text { stry; ERCC } \\
\text { dent kinas } \\
\text { p). }\end{array}$ & $\begin{array}{l}\text { hazard ratio } \mathrm{H} \\
\text { excision repair } \\
\text { inhibitor } 1 \mathrm{~B} ; \mathrm{TL}\end{array}$ & $\begin{array}{l}195 \% \\
\text { cross- } \\
\text { B3: } \beta\end{array}$ & $\begin{array}{l}\text { 1) or tim } \\
\text { mpleme } \\
\text { bulin cla }\end{array}$ & $\begin{array}{l}\text { VSCLC: no } \\
\text { ion group } \\
\text { III; PARP: }\end{array}$ & $\begin{array}{l}\text { mall cell lun } \\
\text { NA: not ava } \\
\text { y (ADP-ribos }\end{array}$ & $\begin{array}{l}\text { cer; ACT: } \\
\text {; SCC: squ } \\
\text { ymerase; }\end{array}$ & $\begin{array}{l}\text { ant chemo } \\
\text { us cell car } \\
\text { ataxia tela }\end{array}$ & $\begin{array}{l}\text { herapy; CDD } \\
\text { inoma; NVB: } \\
\text { giectasia mu }\end{array}$ & $\begin{array}{l}\text { platin; OP: c } \\
\text { elbine; MSH } \\
\# \text { : randomis }\end{array}$ & $\begin{array}{l}\text { olete surger } \\
\text { MutS homol } \\
\text { trial, ACT gr }\end{array}$ & $\begin{array}{l}\text { ry only; IHC: } \\
\text { logue 2; P27 } \\
\text { roup and OP }\end{array}$ \\
\hline
\end{tabular}


TABLE 4 Predictive impact of biomarker gene signatures in NSCLC patients treated with complete resection with or without ACT

\begin{tabular}{|c|c|c|c|c|c|c|c|c|c|c|c|c|}
\hline \multirow{3}{*}{$\begin{array}{l}\text { First author } \\
\text { [ref.] }\end{array}$} & \multirow{3}{*}{$\begin{array}{c}\text { Subjects } \\
n\end{array}$} & \multirow[t]{3}{*}{ Treatment } & \multirow[t]{3}{*}{ Stage } & \multirow[t]{3}{*}{ Method } & \multirow[t]{3}{*}{ Biomarker } & \multirow[t]{3}{*}{ Biomarker expression } & \multicolumn{3}{|c|}{ Disease-free survival } & \multicolumn{3}{|c|}{ Overall survival } \\
\hline & & & & & & & \multirow[t]{2}{*}{ Survival } & \multicolumn{2}{|c|}{$p$-value } & \multirow[t]{2}{*}{ Survival } & \multicolumn{2}{|c|}{ p-value } \\
\hline & & & & & & & & Univariate & Multivariate & & Univariate & Multivariate \\
\hline \multirow[t]{2}{*}{$\begin{array}{l}\text { VAN LAAR } \\
\text { [53] }\end{array}$} & 109 & $\begin{array}{l}\text { ACT (CDDP + } \\
\text { NVB) or OP } \#\end{array}$ & $|-| \mid$ & $\begin{array}{l}\text { Genomic } \\
\text { profiling }\end{array}$ & $\begin{array}{l}\text { 37-gene } \\
\text { signature }\end{array}$ & $\begin{array}{c}\text { Predicted } \\
\text { ACT-responder } \\
\text { (ACT versus OP) }\end{array}$ & NA & NA & NA & $\begin{array}{l}\text { HR: } 0.23 \\
(0.08-0.61)\end{array}$ & NA & 0.0032 \\
\hline & & & & & & $\begin{array}{c}\text { Predicted } \\
\text { nonresponder (ACT } \\
\text { versus } \mathrm{OP} \text { ) }\end{array}$ & NA & NA & NA & $\begin{array}{l}\text { HR: } 0.55 \\
(0.15-2.04)\end{array}$ & NA & 0.38 \\
\hline \multirow[t]{2}{*}{ Zни [31] } & 133 & $\begin{array}{l}\text { ACT (CDDP + } \\
\text { NVB) or OP\# }\end{array}$ & |B-II & RT-PCR & $\begin{array}{l}\text { 15-gene } \\
\text { signature }\end{array}$ & $\begin{array}{l}\text { High risk signature } \\
\text { (ACT versus OP) }\end{array}$ & NA & NA & NA & $\begin{array}{l}\text { HR: } 0.4 \\
(0.18-0.90)\end{array}$ & 0.017 & NA \\
\hline & & & & & & $\begin{array}{c}\text { Low risk signature (ACT } \\
\text { versus } \mathrm{OP} \text { ) }\end{array}$ & NA & NA & NA & $\begin{array}{l}\text { HR: } 1.28 \\
(0.65-2.52)\end{array}$ & 0.476 & NA \\
\hline \multirow[t]{2}{*}{ Chen [32] } & 133 & $\begin{array}{l}\text { ACT (CDDP + } \\
\text { NVB) or OP\# }\end{array}$ & $|-|||$ & $\begin{array}{l}\text { DNA } \\
\text { microarray }\end{array}$ & $\begin{array}{l}\text { 92-gene } \\
\text { signature }\end{array}$ & $\begin{array}{l}\text { High risk signature } \\
\text { (ACT versus OP) }\end{array}$ & NA & NA & NA & $\begin{array}{c}72.2 \% \text { versus } \\
39.2 \%\end{array}$ & 0.03 & NA \\
\hline & & & & & & $\begin{array}{c}\text { Low risk signature (ACT } \\
\text { versus } \mathrm{OP} \text { ) }\end{array}$ & NA & NA & NA & $\begin{array}{c}71.4 \% \text { versus } \\
70.4 \%\end{array}$ & 0.24 & NA \\
\hline Wistuba [34] & 207 & $\begin{array}{l}\text { ACT (NA) or } \\
\text { OPף }\end{array}$ & I-IIB & qPCR & $\begin{array}{l}\text { 31-gene } \\
\text { signature }\end{array}$ & High CCP score & NA & NA & NA & $\begin{array}{c}\text { Greater } \\
\text { absolute ACT } \\
\text { benefit }\end{array}$ & 0.0060 & 0.024 \\
\hline
\end{tabular}

Survival data are presented as hazard ratio (HR) (95\% CI) or \% 5-year survival. NSCLC: nonsmall cell lung cancer; ACT: adjuvant chemotherapy; CDDP: cisplatin; NVB: vinorelbine; OP: complete surgery only; NA: not available; RT-PCR: reverse transcriptase PCR; qPCR: quantitative PCR; CCP: cell cycle progression gene. ${ }^{\#}$ : randomised trial, ACT group and OP group (control group); "? not randomised patients, ACT group and OP group (control group). 
Gene signatures

15-gene signature

In 2010, ZHu et al. [31] presented a 15-gene signature that divided patients into either a high-risk or a low-risk group. The patients with a high-risk gene signature did benefit from ACT with improved OS (HR 0.4, 95\% CI 0.18-0.90; $\mathrm{p}=0.017$ ), while this was not the case for patients in the low-risk group (HR 1.28, 95\% CI $0.65-2.52 ; \mathrm{p}=0.467)$.

37-gene signature

In 2012, VAN LAAR [53] presented a 37-gene signature that divided a group of 109 NSCLC patients (stage I-II) into "predicted ACT-responders" and "predicted nonresponders". Patients in the predicted ACT-responder group receiving ACT had a better OS compared with patients in that group not receiving ACT (HR 0.23, 95\% CI 0.08-0.61; $\mathrm{p}=0.0032$ ). Comparing ACT versus control in the predicted nonresponders resulted in a hazard ratio of 0.55 (95\% CI $0.15-2.04 ; \mathrm{p}=0.38)$.

\section{2-gene signature}

CHEN et al. [32] used a gene signature well known in a breast cancer setting and modified it to fit in an adjuvant setting for early stage NSCLC. 133 NSCLC patients (stage I-III) were included and divided into a high-risk and a low-risk group. Patients in the high-risk group receiving ACT had a better OS compared with patients in the high-risk group not receiving ACT (5-year OS: $72.2 \%$ versus 39.2\%; $\mathrm{p}=0.03$ ). Comparing ACT versus control in the low-risk group showed no significant difference, with a 5 -year OS of $71.4 \%$ versus $70.4 \%(\mathrm{p}=0.24)$.

\section{1-gene signature (CCP score)}

As mentioned earlier, Wistuba et al. [34] presented results on a gene profile including 31 cell cycle progression genes (CCP score). Results on four different populations were presented, but only one population had an observation group and an ACT group. Thus, only the latter result is presented in this section. The prediction on adjuvant treatment benefit was examined in a group of 207 patients among whom 46 received chemotherapy. High CCP score (cut-off: median value) had a greater absolute treatment benefit compared with patients with low CCP score $(\mathrm{p}=0.024)$.

Results on poly (ADP-ribose) polymerase (PARP1) and ataxia telangiectasia mutated (ATM) are presented in table 3.

\section{Discussion}

Articles regarding the biomarkers examined in this review reveal considerable heterogeneity with respect to results. The reasons for these variations are multiple and are discussed in the following sections.

\section{Patient characteristics}

Study designs may be different and, therefore, results may vary between patients participating in a clinical randomised trial with a treatment and control group versus a group of unselected patients outside a trial without a control group. Most articles in this review have included patient populations with various frequencies of disease stages I-III, which is one of many patient characteristics known to confer different prognosis [9], hence influencing the results. PESTA et al. [17] observed that stage II patients had significantly lower mRNA expression of RRM1 and BRCA1 compared with patients in stage I and III $(\mathrm{p}=0.005)$. Thus, the composition of stages in a study group may be decisive for outcome.

Three out of four articles including patients with NSCLC stage I-III found stage III to be an adverse prognostic marker for both DFS and OS compared with stage I-II $[30,55,56]$. Another article presented a different result, with stage IIIA revealing better OS compared with stage I-II (HR 0.64, 95\% CI 0.52-0.78; $\mathrm{p}=0.001$ ) [57]. KATO et al. [58] reported that among 999 NSCLC patients with stage I, T2 status compared with T1 status was associated with worse OS (HR 1.95, 95\% CI 1.41-2.69; $\mathrm{p}=0.001$ ).

Age is another patient characteristic that influences outcome. Older age is associated with poor prognosis. Age $\geqslant 65$ years was associated with poor OS (HR 2.02, 95\% CI 1.46-2.80; $\mathrm{p}=0.001$ ) compared with patients $<65$ years [58]. In another study, age $<55$ years was associated with better OS (HR 0.76, 95\% CI 0.62-0.93; $\mathrm{p}=0.005)$ compared with patients $\geqslant 55$ years [57].

With respect to sex, SÈvE et al. [14] reported that high TUBB3 was more common in female patients ( $\mathrm{p}=0.04)$. BePLER et al. [51] also found that high ERCC1 and RRM1 was more frequent in females $(\mathrm{p}=0.04)$, while Tsao et al. [23] observed that high expression of p53 was more frequent in male patients $(\mathrm{p}=0.04)$.

Male sex has also been linked to poor OS and DFS. NAKAGAwa et al. [59] found male sex to be associated with poorer OS (HR 1.95, 95\% CI 1.11-3.60; p=0.019); likewise SCAGLIOTTI et al. [56] found that male 
patients had a worse OS compared with females (HR 1.33, 95\% CI 1.02-1.72; $\mathrm{p}=0.034$ ). In a third article, KATO et al. [58] found females to have better OS (HR 0.66, 95\% CI 0.48-0.91; p=0.01). TAKENAKA et al. [55] reported males to have worse DFS (HR 5.4, 95\% CI 1.61-18.2; $\mathrm{p}=0.03$ ).

It is frequently observed that expression of biomarkers may vary between histological subtypes $[14,15,18$, $22,23,25,26,51]$, which is another reason that the prognostic and predictive potential may vary depending on the frequencies of various histological subtypes in the study populations. Some articles in this review included several histological subtypes, while other articles focused solely on one histological subtype (tables 1-4), which needs to be kept in mind when comparing different studies on the same biomarker.

BENNOUNA et al. [60] reported adenocarcinoma to be predictive of benefit from ACT (cisplatin-based), with a gain of $13.9 \%$ on 5 -year survival versus a $5.8 \%$ gain in patients with other histologies (HR 0.71, 95\% CI 0.52-0.97), when comparing survival in the two groups ACT versus no ACT for each type of histology (adenocarcinoma and "other histology").

Two studies reported histology as prognostic for outcome. YAN et al. [30] reported that patients with adenocarcinoma had worse DFS (HR 2.14, 95\% CI 1.37-3.37; p=0.001) compared with patients with other histological subtypes. By contrast, TAKENAKA et al. [55] found that adenocarcinoma seemed to have better DFS (HR 0.42, 95\% CI 0.18-0.94; $\mathrm{p}=0.04$ ) compared with other histological subtypes.

Two articles solely including completely resected stage IB patients treated with ACT or observation found that tumour size $\geqslant 4 \mathrm{~cm}$ was predictive for OS [61, 62] (HR 0.69, 95\% CI 0.48-0.99; $\mathrm{p}=0.042$ [62]) and one of these articles also found tumour size to be predictive for DFS (HR 0.69, 95\% CI 0.49-0.97; p=0.035) [62].

Further details of the predictive and prognostic impact of patient characteristics can be found in the online supplementary material.

\section{Examination of biomarkers}

The methodology applied when examining biomarkers often differs between studies, e.g. the antibody used to evaluate expression by IHC, the cut-off levels determining high/low or positive/negative scores, or the scoring itself differs due to tumour heterogeneity or interobserver differences. The relevant examination methods and their cut-off values and challenges are discussed below.

IHC is a well-known and relatively cheap method that uses antibodies to detect the presence/expression of specific biomarkers. A common cut-off value in IHC is the median $\mathrm{H}$-score, which separates patients into two groups: high (positive) and low (negative). An $\mathrm{H}$-score is calculated for staining of each subcellular compartment for normal and tumour cells using the following formula, where $0-3$ is the intensity of the staining and $\%$ is the percentage of the cells with that intensity [63]:

$$
\text { H-score }=(\% \text { at } 0) \times 0+(\% \text { at } 1+) \times 1+(\% \text { at } 2+) \times 2+(\% \text { at } 3+) \times 3
$$

Thus, the H-score normally ranges from 0 to 300, but other IHC scores and cut-off points are also used.

PCR or reverse transcriptase (RT)-PCR measures functionality of single genes through amplification of DNA or mRNA [64]. Most of the articles in this review that examined biomarkers with PCR have used the minimum p-value method to define gene expression levels as high (positive) or low (negative), i.e. the cut-off is decided by a cut-off that yields the most significant result (the lowest p-value).

Gene expression profiling is a technique that examines the expression of many genes at the same time. gene expression profiling divides patients into high-/low-risk or responder/nonresponder groups. There are different techniques for gene expression profiling, including DNA microarray, RT-PCR and microRNA, all of which have pros and cons [65].

As the methods of examination of biomarkers vary it is important to bear in mind that this may also influence the outcome of the study. For example, in 2012 Vilmar et al. [66] examined four biomarkers (ERCC1, BRCA1, RRM1 and TUBB3) with IHC and RT-PCR. When analysing the samples with IHC there was found to be a significant difference in OS in two of the four biomarkers. However, no difference was found in OS when examining the same biomarkers on the same patient samples using RT-PCR.

Another examination challenge is the importance of having a specific antibody that works well when using IHC. One example is the biomarker ERCC1, which is discussed by Friboulet et al. [39]. Friboulet et al. [39] discovered that using the currently available ERCC1 antibodies for IHC analysis did not specifically detect the functional ERCC1 isoform, but also included one or more of the three nonfunctional isoforms. It was, thus, concluded that the usefulness of ERCC1 in therapeutic decision making was restricted and it emphasised the importance of evaluating isoforms of biomarkers and their function.

For both biomarkers and gene expression profiling the importance of validation is essential; however, this is both difficult and challenging $[65,67]$. Not only is validation of the specific biomarker or gene profile 
important but also a decision on a universal usable cut-off value that will be the same for all future analyses. No predictive marker has so far been validated in a prospective trial.

Some biomarkers are well known and used in advanced NSCLC, such as the EML4-ALK-mutation that is predictive for crizotinib treatment [68] and the epidermal growth factor receptor (EGFR) mutation that is predictive for treatment with tyrosine kinase inhibitors such as erlotinib, gefitinib or afatinib [69-71]. However, until recently they had not been examined in an adjuvant setting. In the advanced setting the EGFR mutation has only shown a positive difference in PFS but not OS. Results on EGFR mutations in an adjuvant setting were recently presented at the annual American Society of Clinical Oncology meeting 2014. SHEPHERD et al. [72] and KeLLY et al. [73] presented results from the RADIANT trial. 973 NSCLC patients (stage IB-IIIA) were randomised to adjuvant erlotinib or placebo after surgical resection. These results were, however, not completely mature and median OS had not yet been reached. Although positive EGFR mutation seemed to have a value in predicting response to adjuvant erlotinib in terms of DFS in a subgroup of EGFR-mutated patients (HR 0.61, 95\% CI 0.384-0.981; p=0.0391), this result was not significant due to hierarchical testing. Pennell et al. [74] also presented results on early stage (I-IIIA) NSCLC, EGFR-mutated patients and erlotinib's positive effect on DFS. Median OS had not yet been reached. There was no control or placebo group and the erlotinib was given after standard ACT and/or radiotherapy, making it difficult to conclude the true value of the EGFR mutation's usefulness in an adjuvant setting.

\section{Conclusion}

There is, as yet, no convincing biomarker ready to use in an adjuvant setting regarding completely resected NSCLC. Some biomarkers are promising, for example TUBB3, p53, RRM1, iNTR, BAG-1, p27 and different gene signatures, but are not yet fully validated, although some are associated either with better prognosis (TUBB3, p53, RRM1, iNTR, BAG-1 and 15-gene signature) or predict benefit from ACT (p27 (kip1), p53, TUBB3 and 37-gene signature) in completely resected NSCLC stage I-IIIA. Further investigation and especially validation is required before one or more biomarkers are ready for use in a clinical everyday setting outside of clinical trials. Another thing that will, most likely, be necessary in order to use biomarkers are international standards for examination and screening of expression of individual biomarkers, ensuring that the same biomarker is universally examined in the same (validated) way. Challenges regarding validation of biomarkers include the optimal study design in large randomised trials.

In the future it is possible that a signature of several biomarkers in combination, instead of a single biomarker, may be useful to get a more precise prediction of which patients to treat and with which type of chemotherapy. Hopefully, biomarkers may help to further customise adjuvant treatment for stage I-IIIA, especially treatment of stage IB patients where standard treatment after resection yet remains to be clarified.

\section{References}

1 World Health Organization (WHO). Cancer. Fact sheet no. 297. www.who.int/mediacentre/factsheets/fs297/en/ Date last acccessed: November 28, 2013. Date last updated: February 2014.

Jemal A, Siegel R, Xu J, et al. Cancer statistics, 2010. CA Cancer J Clin 2010; 60: 277-300.

Herbst RS, Heymach JV, Lippman SM et al. Lung cancer. N Engl J Med 2008; 359: 1367-1380.

Ettinger DS, Akerley W, Borghaei H, et al. Non-small cell lung cancer, version 2.2013. J Natl Compr Canc Netw 2013; 11: 645-653.

5 Chemotherapy in non-small cell lung cancer: a meta-analysis using updated data on individual patients from 52 randomised clinical trials. Non-small Cell Lung Cancer Collaborative Group. BMJ 1995; 311: 899-909.

6 Stewart LA, Burdett S, Tierney F, et al. Surgery and adjuvant chemotherapy (CT) compared to surgery alone in non-small cell lung cancer (NSCLC): a meta-analysis using individual patient data (IPD) from randomized clinical trials (RCT). J Clin Oncol 2007; 25: Suppl. 18, 7552.

7 Pignon JP, Tribodet H, Scagliotti GV, et al. Lung adjuvant cisplatin evaluation: a pooled analysis by the LACE Collaborative Group. J Clin Oncol 2008; 26: 3552-3559.

8 Crinò L, Weder W, van Meerbeeck J, et al. Early stage and locally advanced (non-metastatic) non-small-cell lung cancer: ESMO Clinical Practice Guidelines for diagnosis, treatment and follow-up. Ann Oncol 2010; 21: Suppl. 5, v103-v115.

9 Goldstraw P, Crowley J, Chansky K, et al. The IASLC Lung Cancer Staging Project: proposals for the revision of the TNM stage groupings in the forthcoming (seventh) Edn of the TNM Classification of malignant tumours. J Thorac Oncol 2007; 2: 706-714.

10 Detterbeck FC, Lewis SZ, Diekemper R, et al. Executive Summary: Diagnosis and management of lung cancer, 3rd ed: American College of Chest Physicians evidence-based clinical practice guidelines. Chest 2013; 143: Suppl. 5, 7S-37S.

11 McShane LM, Altman DG, Sauerbrei W, et al. Reporting recommendations for tumor marker prognostic studies (REMARK). J Natl Cancer Inst 2005; 97: 1180-1184.

12 Hayes DF, Trock B, Harris AL. Assessing the clinical impact of prognostic factors: when is "statistically significant" clinically useful? Breast Cancer Res Treat 1998; 52: 305-319.

13 Ilie M, Hofman V, Ortholan C, et al. Predictive clinical outcome of the intratumoral CD66b-positive neutrophil-to-CD8-positive T-cell ratio in patients with resectable nonsmall cell lung cancer. Cancer 2012; 118: 1726-1737. 
14 Sève P, Lai R, Ding K, et al. Class III beta-tubulin expression and benefit from adjuvant cisplatin/vinorelbine chemotherapy in operable non-small cell lung cancer: analysis of NCIC JBR.10. Clin Cancer Res 2007; 13: 994-999.

15 Reiman T, Lai R, Veillard AS, et al. Cross-validation study of class III beta-tubulin as a predictive marker for benefit from adjuvant chemotherapy in resected non-small-cell lung cancer: analysis of four randomized trials. Ann Oncol 2012; 23: 86-93.

16 Okuda K, Sasaki H, Dumontet C, et al. Expression of excision repair cross-complementation group 1 and class III beta-tubulin predict survival after chemotherapy for completely resected non-small cell lung cancer. Lung Cancer 2008; 62: 105-112.

17 Pesta M, Kulda V, Fiala O, et al. Prognostic significance of ERCC1, RRM1 and BRCA1 in surgically-treated patients with non-small cell lung cancer. Anticancer Res 2012; 32: 5003-5010.

18 Olaussen KA, Dunant A, Fouret P, et al. DNA repair by ERCC1 in non-small-cell lung cancer and cisplatin-based adjuvant chemotherapy. $N$ Engl J Med 2006; 355: 983-991.

19 Leng XF, Chen MW, Xian L, et al. Combined analysis of mRNA expression of ERCC1, BAG-1, BRCA1, RRM1 and TUBB3 to predict prognosis in patients with non-small cell lung cancer who received adjuvant chemotherapy. J Exp Clin Cancer Res 2012; 31: 25.

20 Cubukcu E, Fatih Olmez O, Saraydaroglu O, et al. Immunohistochemical expression of excision repair cross-complementing 1 (ERCC1) in non-small-cell lung cancer: implications for patient outcome. Clin Transl Oncol 2011; 13: 826-830.

21 Pierceall WE, Olaussen KA, Rousseau V, et al. Cisplatin benefit is predicted by immunohistochemical analysis of DNA repair proteins in squamous cell carcinoma but not adenocarcinoma: theranostic modeling by NSCLC constituent histological subclasses. Ann Oncol 2012; 23: 2245-2252.

22 Graziano SL, Gu L, Wang X, et al. Prognostic significance of mucin and p53 expression in stage IB non-small cell lung cancer: a laboratory companion study to CALGB 9633. J Thorac Oncol 2010; 5: 810-817.

23 Tsao MS, Aviel-Ronen S, Ding K, et al. Prognostic and predictive importance of p53 and RAS for adjuvant chemotherapy in non small-cell lung cancer. J Clin Oncol 2007; 25: 5240-5247.

24 Filipits M, Haddad V, Schmid K, et al. Multidrug resistance proteins do not predict benefit of adjuvant chemotherapy in patients with completely resected non-small cell lung cancer: International Adjuvant Lung Cancer Trial Biologic Program. Clin Cancer Res 2007; 13: 3892-3898.

25 Kamal NS, Soria JC, Mendiboure J, et al. MutS homologue 2 and the long-term benefit of adjuvant chemotherapy in lung cancer. Clin Cancer Res 2010; 16: 1206-1215.

26 Nakano J, Huang C, Liu D, et al. Evaluations of biomarkers associated with 5-FU sensitivity for non-small-cell lung cancer patients postoperatively treated with UFT. Br J Cancer 2006; 95: 607-615.

27 Miyoshi T, Kondo K, Toba $\mathrm{H}$, et al. Predictive value of thymidylate synthase and dihydropyrimidine dehydrogenase expression in tumor tissue, regarding the efficacy of postoperatively administered UFT (tegafur +uracil) in patients with non-small cell lung cancer. Anticancer Res 2007; 27: 2641-2648.

28 Shi Y, Chen L, Li J, et al. Prognostic and predictive values of pERK1/2 and pAkt-1 expression in non-small cell lung cancer patients treated with adjuvant chemotherapy. Tumour Biol 2011; 32: 381-390.

29 Voortman J, Goto A, Mendiboure J, et al. MicroRNA expression and clinical outcomes in patients treated with adjuvant chemotherapy after complete resection of non-small cell lung carcinoma. Cancer Res 2010; 70: 8288-8298.

30 Yan S, Shun-Chang J, Li C, et al. Topoisomerase II alpha expression and the benefit of adjuvant chemotherapy for postoperative patients with non-small cell lung cancer. BMC Cancer 2010; 10: 621.

31 Zhu CQ, Ding K, Strumpf D, et al. Prognostic and predictive gene signature for adjuvant chemotherapy in resected non-small-cell lung cancer. J Clin Oncol 2010; 28: 4417-4424.

32 Chen DT, Hsu YL, Fulp WJ, et al. Prognostic and predictive value of a malignancy-risk gene signature in early-stage non-small cell lung cancer. J Natl Cancer Inst 2011; 103: 1859-1870.

33 Kratz JR, He J, Van Den Eeden SK, et al. A practical molecular assay to predict survival in resected non-squamous, non-small-cell lung cancer: development and international validation studies. Lancet 2012; 379 : 823-832.

34 Wistuba II, Behrens C, Lombardi F, et al. Validation of a proliferation-based expression signature as prognostic marker in early stage lung adenocarcinoma. Clin Cancer Res 2013; 19: 6261-6271.

35 Levallet G, Bergot E, Antoine M, et al. High TUBB3 expression, an independent prognostic marker in patients with early non-small cell lung cancer treated by preoperative chemotherapy, is regulated by K-Ras signaling pathway. Mol Cancer Ther 2012; 11: 1203-1213.

36 Stubbe J. Ribonucleotide reductases in the twenty-first century. Proc Natl Acad Sci USA 1998; 95: 2723-2724.

37 Zheng Z, Chen T, Li X, et al. DNA synthesis and repair genes RRM1 and ERCC1 in lung cancer. N Engl J Med 2007; 356: 800-808.

38 Altaha R, Liang X, Yu JJ, et al. Excision repair cross complementing-group 1: gene expression and platinum resistance. Int J Mol Med 2004; 14: 959-970.

39 Friboulet L, Olaussen KA, Pignon JP, et al. ERCC1 isoform expression and DNA repair in non-small-cell lung cancer. N Engl J Med 2013; 368: 1101-1110.

40 Paterson JW. BRCA1: a review of structure and putative functions. Dis Markers 1998; 13: 261-274

41 Wachters FM, Wong LS, Timens W, et al. ERCC1, hRad51, and BRCA1 protein expression in relation to tumour response and survival of stage III/IV NSCLC patients treated with chemotherapy. Lung Cancer 2005; 50: 211-219.

42 Rosell R, Skrzypski M, Jassem E, et al. BRCA1: a novel prognostic factor in resected non-small-cell lung cancer. PLoS One 2007; 2: el129.

43 May P, May E. Twenty years of p53 research: structural and functional aspects of the p53 protein. Oncogene 1999; 18: 7621-7636.

44 Deeley RG, Westlake C, Cole SP. Transmembrane transport of endo- and xenobiotics by mammalian ATP-binding cassette multidrug resistance proteins. Physiol Rev 2006; 86: 849-899.

45 Zdraveski ZZ, Mello JA, Farinelli CK, et al. MutS preferentially recognizes cisplatin- over oxaliplatin-modified DNA. J Biol Chem 2002; 277: 1255-1260. 

O6-methylguanine, O4-methylthymine, or the cisplatin-d(GpG) adduct. Proc Natl Acad Sci USA 1996; 93: 6443-6447.

47 Kaneda S, Nalbantoglu J, Takeishi K, et al. Structural and functional analysis of the human thymidylate synthase gene. J Biol Chem 1990; 265: 20277-20284.

48 Krajewska M, Turner BC, Shabaik A, et al. Expression of BAG-1 protein correlates with aggressive behavior of prostate cancers. Prostate 2006; 66: 801-810.

49 Liu H, Liang Y, Li Y, et al. Gene silencing of BAG-1 modulates apoptotic genes and sensitizes lung cancer cell lines to cisplatin-induced apoptosis. Cancer Biol Ther 2010; 9: 832-840.

50 Kellner U, Sehested M, Jensen PB, et al. Culprit and victim - DNA topoisomerase II. Lancet Oncol 2002; 3: 235-243.

51 Bepler G, Olaussen KA, Vataire AL, et al. ERCC1 and RRM1 in the international adjuvant lung trial by automated quantitative in situ analysis. Am J Pathol 2011; 178: 69-78.

52 Filipits M, Pirker R, Dunant A, et al. Cell cycle regulators and outcome of adjuvant cisplatin-based chemotherapy in completely resected non-small-cell lung cancer: the International Adjuvant Lung Cancer Trial Biologic Program. J Clin Oncol 2007; 25: 2735-2740.

53 Van Laar RK. Genomic signatures for predicting survival and adjuvant chemotherapy benefit in patients with non-small-cell lung cancer. BMC Med Genomics 2012; 5: 30.

54 Polyak K, Lee MH, Erdjument-Bromage H, et al. Cloning of p27Kip1, a cyclin-dependent kinase inhibitor and a potential mediator of extracellular antimitogenic signals. Cell 1994; 78: 59-66.

55 Takenaka T, Yano T, Kiyohara C, et al. Effects of excision repair cross-complementation group 1 (ERCC1) single nucleotide polymorphisms on the prognosis of non-small cell lung cancer patients. Lung Cancer 2010; 67: $101-107$.

56 Scagliotti GV, Fossati R, Torri V, et al. Randomized study of adjuvant chemotherapy for completely resected stage I, II, or IIIA non-small-cell lung cancer. J Natl Cancer Inst 2003; 95: 1453-1461.

57 Douillard JY, Rosell R, De Lene M, et al. Adjuvant vinorelbine plus cisplatin versus observation in patients with completely resected stage IB-IIIA non-small-cell lung cancer (Adjuvant Navelbine International Trialist Association [ANITA]): a randomised controlled trial. Lancet Oncol 2006; 7: 719-727.

58 Kato H, Ichinose Y, Ohta M, et al. A randomized trial of adjuvant chemotherapy with uracil-tegafur for adenocarcinoma of the lung. N Engl J Med 2004; 350: 1713-1721.

59 Nakagawa K, Tada H, Akashi A, et al. Randomised study of adjuvant chemotherapy for completely resected p-stage I-IIIA non-small cell lung cancer. Br J Cancer 2006; 95: 817-821.

60 Bennouna J, Senellart H, Hiret S, et al. Impact of histology on survival of resected non-small cell lung cancer (NSCLC) receiving adjuvant chemotherapy: subgroup analysis of the adjuvant vinorelbine (NVB) cisplatin (CDDP) versus observation in the ANITA trial. Lung Cancer 2011; 74: 30-34.

61 Butts CA, Ding K, Seymour L, et al. Randomized phase III trial of vinorelbine plus cisplatin compared with observation in completely resected stage IB and II non-small-cell lung cancer: updated survival analysis of JBR-10. J Clin Oncol 2010; 28: 29-34.

62 Strauss GM, Herndon JE 2nd, Maddaus MA, et al. Adjuvant paclitaxel plus carboplatin compared with observation in stage IB non-small-cell lung cancer: CALGB 9633 with the Cancer and Leukemia Group B, Radiation Therapy Oncology Group, and North Central Cancer Treatment Group Study Groups. J Clin Oncol 2008; 26: 5043-5051

63 McCarty KS Jr, Szabo E, Flowers JL, et al. Use of a monoclonal anti-estrogen receptor antibody in the immunohistochemical evaluation of human tumors. Cancer Res 1986; 46: Suppl., 4244s-4248s.

64 Deepak S, Kottapalli K, Rakwal R, et al. Real-time PCR: revolutionizing detection and expression analysis of genes. Curr Genomics 2007; 8: 234-251.

65 Petrosyan F, Daw H, Haddad A, et al. Gene expression profiling for early-stage NSCLC. Am J Clin Oncol 2015; 38: $103-107$.

66 Vilmar A, Garcia-Foncillas J, Huarriz M, et al. RT-PCR versus immunohistochemistry for correlation and quantification of ERCC1, BRCA1, TUBB3 and RRM1 in NSCLC. Lung Cancer 2012; 75: 306-312.

67 Bergot E, Levallet G, Campbell K, et al. Predictive biomarkers in patients with resected non-small cell lung cancer treated with perioperative chemotherapy. Eur Respir Rev 2013; 22: 565-576.

68 Shaw AT, Kim DW, Nakagawa K, et al. Crizotinib versus chemotherapy in advanced ALK-positive lung cancer. N Engl I Med 2013; 368: 2385-2394.

69 Rosell R, Carcereny E, Gervais R, et al. Erlotinib versus standard chemotherapy as first-line treatment for European patients with advanced EGFR mutation-positive non-small-cell lung cancer (EURTAC): a multicentre, open-label, randomised phase 3 trial. Lancet Oncol 2012; 13: 239-246.

70 Mitsudomi T, Morita S, Yatabe Y, et al. Gefitinib versus cisplatin plus docetaxel in patients with non-small-cel lung cancer harbouring mutations of the epidermal growth factor receptor (WJTOG3405): an open label, randomised phase 3 trial. Lancet Oncol 2010; 11: 121-128.

71 Sequist LV, Yang JC, Yamamoto N, et al. Phase III study of afatinib or cisplatin plus pemetrexed in patients with metastatic lung adenocarcinoma with EGFR mutations. J Clin Oncol 2013; 31: 3327-3334.

72 Shepherd FA, Altorki NK, Eberhardt WE, et al. Adjuvant erlotinib (E) versus placebo (P) in non-small cell lung cancer (NSCLC) patients (pts) with tumors carrying EGFR-sensitizing mutations from the RADIANT trial. $J$ Clin Oncol 2014; 32: Suppl. 15, 7513.

73 Kelly K, Altorki NK, Eberhardt WE, et al. A randomized, double-blind phase 3 trial of adjuvant erlotinib (E) versus placebo $(\mathrm{P})$ following complete tumor resection with or without adjuvant chemotherapy in patients (pts) with stage IB-IIIA EGFR positive (IHC/FISH) non-small cell lung cancer (NSCLC): RADIANT results. $J$ Clin Oncol 2014; 32: Suppl. 15, 7501.

74 Pennell NA, Neal JW, Chaft JE, et al. SELECT: A multicenter phase II trial of adjuvant erlotinib in resected early-stage EGFR mutation-positive NSCLC. J Clin Oncol 2014; 32: Suppl. 15, 7514. 